\title{
EVOLUCION DE LAS TEORIAS COGNITIVAS Y SUS APORTES A LA EDUCACIÓN
}

Cáceres Zoraya.${ }^{1}$, Munévar Olga. ${ }^{1}$

${ }^{1}$ Fisioterapeuta, Candidata a Doctor en Educación, Magíster en Ciencias de la Actividad Física y el Deporte. Especialista en Pedagogía Universitaria. Docente de la Universidad de Pamplona Colombia. Correo electrónico: zcaceres@unipamplona.edu.co

${ }^{1}$ Fisioterapeuta, Candidata a Doctor en Educación, Magíster en Educación. Especialista en Gerencia en Salud Ocupacional. Docente de la Universidad de Pamplona Colombia. Correo electrónico: olgamunevar@unipamplona.edu.co

\section{RESUMEN:}

Las Teorías Cognitivas determinan que los diferentes procesos del aprendizaje pueden ser explicados, por medio del análisis de los procesos mentales, los intervinientes del medio ambiente y las posturas actitudinales de docentes y estudiantes. Presupone que, por medio de procesos cognitivos efectivos, el aprendizaje resulta más fácil y la nueva información puede ser almacenada en la memoria por mucho tiempo. Por el contrario, los procesos cognitivos ineficaces producen dificultades en el aprendizaje que pueden ser observadas a lo largo de la vida de un individuo. Pareciese que el estudio del proceso enseñanza - aprendizaje atañe exclusivamente a los pedagogos; pero hoy la gran variedad de investigaciones desmiente tal apreciación y afirman que se debe involucrar toda persona que ejerce la docencia; independiente de su profesión; su conocimiento en el desarrollo de la cognición y cómo se aprende, se verá reflejado en su quehacer docente y por ende en la calidad de sus estudiantes. Como respaldo a la anterior premisa, se realizó una revisión de los postulados de Tolman, Gestalt, Piaget, Ausubel, Bruner, Vygotsky, Feuerstein, Gagné, Goleman, Gardner y la Neurociencia, de donde se derivaron los aportes a la educación actual de cada uno de ellos.

PALABRAS CLAVE: teorías, aprendizaje, enseñanza, inteligencia, neurociencia.

\section{EVOLUTION OF COGNITIVE THEORIES AND THEIR CONTRIBUTIONS TO EDUCATION}

\begin{abstract}
Cognitive Theories determine that different learning processes can be explained through analysis of mental processes, environmental involved and attitudinal stances of teachers and students. It presupposes that, through effective cognitive processes, learning becomes easier and the new information can be stored in memory longer. Conversely, ineffective cognitive processes generate learning difficulties that can be observed throughout an individual's life. It seems that the study of the teaching process- learning relates exclusively to educators; but nowadays most of researches contradicts that assessment and argue that it should involve everyone who has been teaching;
\end{abstract}


regardless of their profession; their knowledge in the development of cognition and how to learn, will be reflected in their teaching work and therefore in the quality of its students. In support of this premise, a review of the principles of Tolman, Gestalt, Piaget, Ausubel, Bruner, Vygotsky, Feuerstein, Gagné, Goleman, Gardner and Neuroscience was held, where current contributions to education stemmed each one of them.

KEYWORDS: theories; learning; teachin; intelligence; neuroscience

\section{INTRODUCCIÓN}

El cognitivismo es una corriente teórica también conocida como psicología cognitiva, que surge en la década de los sesenta y que estudia el proceso de aprendizaje desde la lógica de los procesos de información (Mayer, 1985). El enfoque Cognoscitivo como tendencia pedagógica moderna se fundamenta en el análisis de los aspectos psicológicos existentes, de manera obligada, en los procesos que conducen al conocimiento de la realidad objetiva, natural y propia, del hombre. Sustentada en la teoría del conocimiento desde el punto de vista filosófico, considera al mismo como el resultado y la consecuencia de la búsqueda, consciente y consecuente, que unida a la acción real del sujeto sobre su entorno le permiten su reflejo en lo interno. Esta tendencia pedagógica contemporánea se plantea la concepción y desarrollo de modelos de aprendizaje como formas de expresión de una relación concreta entre el sujeto cognitivo, activo y el objeto cuyas esencialidades habrán de ser aprendidas y niega que todo conocimiento humano consista o sea una mera construcción personal por parte del sujeto, a punto de partida de la imprescindible información sensorial.

Su definición es compleja dado que hace referencia a un conjunto heterogéneo de teorías que incluye desde los postulados de Piaget a las teorías cognitivas del aprendizaje pasando por las teorías del procesamiento de la información o por las teorías cognitivas de la personalidad. La psicología cognitiva centra su atención en los procesos mentales relacionados con el conocimiento. Según el cognitivismo, el aprendizaje es un proceso de modificación de significados, intencional y que resulta de la interacción entre la nueva información y el sujeto. Según esta corriente, el individuo tiene estructuras cognitivas pre-existentes (esquemas) con los que interactúa la nueva información y en las cuales encaja modificando dichos esquemas.

Históricamente se ha de situar el cognitivismo entre el conductismo, ante el que reacciona, y el constructivismo, del que es precursor. Su desarrollo se produce entre 1950 y 1960, pero su influencia es muy significativa en los años setenta. Dos de sus aportes más relevantes al desarrollo de la psicología en cuanto a ciencia, es el rechazo de la introspección como método de investigación, abrazando el método científico, y la asunción de la existencia de estados mentales internos: creencias, deseos, motivaciones; que habían negado las corrientes conductistas. A los anteriores aportes (Ormrod, 2008), resalta algunos trabajos con una evidente fuerza cognitiva, como son las publicaciones de Noam Chomsky en el ámbito psicolingüístico, y los manuscritos de Brunner, Goodnow y Austín (1956) sobre el aprendizaje conceptual.

\section{Postulados de Tolman: Conducta Propositiva}

Para (Pedraja, 2001) algunas de las más tempranas apreciaciones de la teoría cognitiva estaban en las propuestas del Tolman (1932 - 1959) psicólogo conductista que criticó los postulados absolutistas de Skinner y demostró desde la psicología comportamientos que no se tenían en 
cuenta en el conductismo de la época. Valoraba la objetividad en la investigación y también utilizó especies no humanas en sus estudios. Tolman estadounidense que planteó que el objeto de estudio más apropiado son las conductas más globales y no solo el estímulo - respuesta, que el aprendizaje puede darse en ausencia del reforzamiento, incorporó el término aprendizaje no latente; que es el aprendizaje no observable pero si establecido, expone que existe variables internas como conocimientos previos 0 estados fisiológicos que intervienen en el aprendizaje, que las conductas son intencionadas y que están mediadas por las expectativas porque cuando no se cumplen las expectativas de un organismo; su conducta puede resultar afectada de manera muy adversa.

Tolman demuestra igualmente, que el aprendizaje da lugar a un conjunto organizado de información, desarrollando mapas cognitivos del entorno, es decir, el conocimiento de cómo se organizan las cosas en el espacio permite al organismo ajustarse al medio. Esto lo denominó mapas mentales; estructuras organizadas que se modifican con cada nuevo aprendizaje.

Aportes a la Educación Actual: Los principales aportes de Tolman a la educación es la defensa de que el aprendizaje no tiene lugar por reforzamiento, sino por significación. Cuando un estímulo (signo) va seguido de un segundo estímulo (significado), el sujeto adquirirá una asociación entre estos estímulos. Otro gran aporte, se refiere al aspecto motivacional, como punto de partida a lo que suponga cogniciónmotivación. Las expectativas, para él, son variables motivacionales donde el sujeto relaciona sus creencias-valores, necesidades, su propia imagen, constituyendo un espacio o campo conductual inmediato. Finalmente, la contribución de Tolman que marca la educación, está en el uso de mapas cognitivos y el concepto de que el aprendizaje no es solamente la adquisición de un hábito, sino la creación de una representación interna 0 mental de un camino que conduce al éxito.

\section{Postulados de la Gestalt: Aprendizaje por Insight}

Esta teoría fue concebida por Max Wertheimer (1880-1943) y se desarrolla en Alemania a partir de 1924. Este psicólogo alemán sostenía que la conciencia debía ser estudiada como una totalidad organizada. Los pensamientos son percepciones significativas totales y no un simple conjunto asociado de imágenes 0 de eslabones estimulo-respuesta (E-R). Para los psicólogos gestaltistas según (Pozo, 2006) en el proceso de aprendizaje la experiencia y la percepción son más importantes que las respuestas específicas dadas a cada estímulo. Cuando un individuo comienza un aprendizaje dispone de un conjunto de actitudes, habilidades, expectativas sobre su propia capacidad de aprender conocimientos, y percibe la situación de aprendizaje de una forma particular, distinta de la percepción de otros. De allí que el éxito en el aprendizaje depende de experiencias anteriores.

Cada persona selecciona y organiza los estímulos de acuerdo con sus propias experiencias y no responde a ellos de manera -aislada, sino en relación con la situación como un todo y a sus elementos más significativos. Una persona percibe una forma, una estructura, una configuración u organización, esto es, en idioma alemán, una Gestalt, de lo que deriva la teoría su denominación. Por eso es que la teoría gestáltica formula el principio: El todo es algo más que la simple suma de sus partes. El aprendizaje, ocurre por Insight, esto es, por una especie de comprensión repentina a la que se llega después de tentativas infructuosas en busca de una solución. Por ejemplo, en los casos en que estamos tratando de resolver un problema matemático y no damos con la solución, 0 en otro en el que buscamos un objeto y no recordamos el lugar en que lo dejamos. Después de haber abandonado la tarea o la 
búsqueda, de manera repentina e inesperada encontramos la solución 0 recordamos el lugar donde dejamos el objeto. Es decir el aprendizaje por Insight 0 aparición repentina de la solución, señala que el aprendizaje ocurre como la consecuencia de una comprensión global de la situación y una percepción de sus elementos más significativos.

Aportes a la Educación Actual: Uno de los principales aportes de la teoría de la Gestalt en el campo educativo es proponer un pensamiento productivo, en el cual se debe dar una comprensión estructural, mediante la percepción significativa y una organización de las relaciones. Con esta teoría se presenta una orientación educativa en pro de las capacidades propias y adquiridas de cada ser humano, relacionadas con su creatividad, sus actitudes, valores y con su compromiso consigo mismo y con la sociedad. Para poder llevar a cabo el cometido anterior, el docente debe conocer las características particulares de sus estudiantes y de esta manera ayudarlo para que se produzca la verdadera comprensión de los aprendizajes, es fundamental que el docente esté convencido de la importancia que tiene tratar de atender las particularidades de sus estudiantes respecto a aquello que interesa que aprendan; para lo cual se necesita motivarlo para que forme parte activa de las experiencias de aprendizaje que se presenten.

Postulados de Jean Piaget: Teoría Psicogenética o Epistemología Genética

El proyecto teórico de Piaget fue a lo largo de toda su vida un proyecto epistemológico. Buscó afanosamente fundar los análisis epistemológicos en observaciones empíricas y dar una explicación biológica del conocimiento. Planteó poner fin a la tradición puramente especulativa de la epistemología. Definió por eso a la epistemología como el estudio de la constitución de conocimientos válidos y subraya que el conocimiento es un proceso y que como tal debe ser descrito de manera histórica. Esta epistemología genética necesitaba dos tipos de método para su constitución. Para el aspecto de la validez formal de los conocimientos Piaget recurre a las técnicas de la lógica y para las cuestiones de hecho demanda el control de tipo experimental aportado por la psicología genética y por el análisis histórico, y cultural (sociogenesis).

En términos genéticos, la psicología de J. Piaget según (García, 2001) consiste en un conjunto de estudios que analizan la evolución del intelecto desde el periodo sensoriomotriz del pequeño, hasta el surgimiento del pensamiento conceptual en el adolescente. El punto de vista psicogenético considera los diversos estadios desde dos perspectivas fundamentales: la continua, a través de la asimilación y la acomodación y la discontinua llamada estructuras. La asimilación consiste en la interiorización o internalización de un objeto 0 un evento a una estructura comportamental y cognitiva preestablecida. Mientras la acomodación es el proceso mediante el cual el sujeto modifica sus esquemas (estructuras cognitivas) para poder incorporar a esa estructura cognoscitiva nuevos objetos. Sobre la base de estas premisas Piaget construye una teoría del Desarrollo Psicológico que posteriormente será aplicado al aprendizaje escolar. En ese sentido identifica tres períodos de desarrollo: (a) el periodo sensoriomotriz, (b) el período de preparación y organización de las operaciones concretas y (c) el período de las operaciones formales; periodos que son diferentes en la edad infantil y en la adultez.

Aportes a la Educación Actual: Esta teoría involucra al educador como un orientador 0 facilitador, que permite mediante el cuestionamiento de las diversas situaciones el aprendizaje de sus estudiantes, para lo cual se hace necesario considerarlo como constructor de sus propias adquisiciones educativas y en las 
que la motivación hace parte esencial de propio proceso de construcción. Para que el educador pueda orientar el proceso debe a su vez, conocer el nivel de organización de conocimientos que presentan sus estudiantes y de acuerdo a ello presentar alternativas y situaciones problemáticas que conduzcan a sus estudiantes a la resolución de las mismas, a seguir planteándose preguntas y de ésta manera reorganizar sus conocimientos al mismo tiempo que avanza en los mismos. Piaget le da un valor importante al lenguaje como instrumento de operaciones intelectuales superiores, para lo cual, el conocimiento y el comportamiento resultan del proceso de construcción del sujeto en los intercambios culturales con el medio que lo rodea.

\section{Postulados de David Ausubel: Aprendizaje Significativo}

La propuesta de Ausubel "está centrada en el aprendizaje producido en un contexto educativo, es decir en el marco de una situación de interiorización o asimilación a través de la instrucción" (Pozo, 2006, p.209). Ausubel desarrolló una teoría sobre la interiorización o asimilación, a través de la instrucción, de los conceptos verdaderos, que se construyen a partir de conceptos previamente formados o descubiertos por la persona en su entorno. Como aspectos distintivos de la teoría está la organización del conocimiento en estructuras y las reestructuraciones que se producen debido a la interacción entre esas estructuras presentes en el sujeto y la nueva información. Ausubel considera que para que esa restructuración se produzca se requiere de una instrucción formalmente establecida, que presente de modo organizado y preciso la información que debe desequilibrar las estructuras existentes. La teoría toma como punto de partida la diferenciación entre el aprendizaje y la enseñanza.

La teoría pone el énfasis en lo que ocurre en el aula cuando los estudiantes aprenden; en la naturaleza de ese aprendizaje; en las condiciones que se requieren para que éste se produzca; en sus resultados $y$, consecuentemente, en su evaluación. Ausubel (1976, p.18) sostuvo que "la psicología educativa debe concentrarse en la naturaleza y la facilitación del aprendizaje de la materia de estudio" y eso significa prestar atención, por una parte, a aquellos conocimientos provenientes de la psicología que hacen falta para dar cuenta de dichos procesos; $y$, por otra, a aquellos principios y premisas procedentes de las teorías de aprendizaje que pueden garantizar la significatividad de lo aprendido, sin que ni unos ni otros se constituyan en fines en sí mismos, ya que lo que realmente interesa es que se logre un aprendizaje significativo en el entorno escolar.

La característica más importante del aprendizaje significativo es que produce una interacción entre los conocimientos más relevantes de la estructura cognitiva y las nuevas informaciones (no es una simple asociación), de tal modo que éstas adquieren un significado y son integradas a la estructura cognitiva de manera no arbitraria y sustancial, favoreciendo la diferenciación, evolución y estabilidad de los subsunsores o conceptos pre existentes y consecuentemente de toda la estructura cognitiva.

Aportes a la Educación Actual: Dentro de sus postulaciones, Ausubel destaca que el conocimiento transmitido en el aprendizaje debe estructurarse teniendo en cuenta los conocimientos que posee el estudiante, ya que los nuevos conocimientos que el mismo adquiere, se sientan sobre las bases de los conocimientos adquiridos con anterioridad. En cualquier nivel educativo se precisa una organización y secuenciación de los contenidos educativos ya que dependen de los conocimientos precedentes en los alumnos. Para Ausubel el aprendizaje debe ser una actividad significativa, relacionando los aprendizajes anteriores con los que se adquieren. Propone un aprendizaje progresivo y comprensivo, en tanto lo que se comprende se puede aprender y recordar con mayor facilidad ya que se integra en la 
estructura de conocimientos; igualmente, la disposición positiva del sujeto que aprende está íntimamente relacionada con el material de aprendizaje que se presenta para el logro de un aprendizaje significativo.

\section{Postulados de Jerome Bruner: Teoría del Aprendizaje por Descubrimiento}

La evolución del pensamiento de Jerome Bruner respecto de lo que se entiende por conocimiento y aprendizaje es representativa del debate teórico que la Psicología Cognitiva ha experimentado durante la segunda mitad del siglo XX.

Bruner definiría la representación como "un conjunto de reglas mediante las cuales se puede conservar aquello experimentado en diferentes acontecimientos" (Camargo \& Hederich, 2010, p.330). Representar consistiría entonces en guardar en la memoria aspectos de la experiencia, utilizando para ello algún código regido por reglas. En ese momento, Bruner realiza una de sus mayores contribuciones al tema, al proponer la existencia de tres sistemas básicos de representación presentes en la cognición humana: (a) la representación enactiva, o de esquemas motores; (b) la representación icónica, mediante imágenes de objetos o eventos, y (c) la representación simbólica, usando sistemas formales como el lenguaje. Estas representaciones son concebidas por Bruner como herramientas que pueden ser manipuladas con propósitos definidos, como la solución a un problema 0 la toma de una decisión. Se trata, eso sí, de herramientas mentales que permiten la realización de acciones u operaciones mentales.

La nueva perspectiva bruniana propone a un aprendiz inmerso en un mundo socialcultural y es por la vía de interacción con el otro, en especial la interacción comunicativa con el otro, que es posible construir un mundo con sentido, es decir, aprender (Bruner, 1986). Por tanto, la propuesta elaborada por Bruner, expone que el aprendizaje no debe limitarse a una memorización mecánica de información 0 de procedimientos, sino que debe conducir al educando al desarrollo de su capacidad para resolver problemas y pensar sobre la situación a la que se le enfrenta.

Aportes a la Educación Actual: Jerome Bruner representa la perspectiva con mayor vínculo social y cultural, la cual constituye una de las ideas poderosas en que se originó el paradigma cognitivo. El desarrollo del pensamiento humano se fundamenta en la percepción, la cual se construye en las estructuras mentales. Hay tres niveles de representaciones mentales que son independientes: 1) correspondiente a la acciones habituales del alumno; 2) representa la imagen; 3) vinculado al simbolismo propio del lenguaje. Cuando el alumno se encuentra en una situación desconocida, una de las formas de representación entra en conflicto con las otras, buscando solución al problema las estructuras mentales se potencian a un nivel más elevado del que se dio el conflicto inicialmente. El docente es un facilitador para llevar al alumno a un conocimiento potencial más elevado, mediante el ofrecimiento de tareas prácticas en las que se aplique la información que después será recordada y mediante la selección de los contenidos conectados e integrados en la estructura de conocimiento alcanzada.

\section{Postulados de Lev Vygotsky: Aprendizaje Sociocultural}

La perspectiva evolutiva de Vygotsky es el método principal de su trabajo, señala que un comportamiento sólo puede ser entendido si se estudian sus fases, su cambio, es decir; su historia (Vygotsky, 1979). Uno de los aportes más significativos de la obra de Vygotsky lo constituye la relación que establece entre el pensamiento y el lenguaje. Señala que en el desarrollo ontogenético ambos provienen de distintas raíces genéticas, en el desarrollo del habla del niño se puede establecer con certeza una etapa preintelectual y en su desarrollo intelectual una etapa prelingüística; hasta un cierto punto en el tiempo, las dos siguen líneas separadas, independientemente una de la otra. En un momento determinado 
estas líneas se encuentran y entonces el pensamiento se torna verbal y el lenguaje racional.

Otro de los aportes de Vygotsky se relaciona con el uso de instrumentos mediadores (herramientas y signos) para entender los procesos sociales. La creación y utilización de signos como método auxiliar para resolver un problema psicológico determinado es un proceso análogo a la creación y utilización de herramientas. Vygotsky (1979), señala que todo aprendizaje en la escuela siempre tiene una historia previa, todo niño ya ha tenido experiencias antes de entrar en la fase escolar, por tanto, aprendizaje y desarrollo están interrelacionados desde los primeros días de vida del niño.

La capacidad de los niños, de idéntico nivel de desarrollo mental para aprender bajo la guía de un maestro variaba en gran medida, e igualmente el subsiguiente curso de su aprendizaje sería distinto. Esta diferencia es la que denominó Zona de Desarrollo Próximo: "No es otra cosa que la distancia entre el nivel real de desarrollo, determinado por la capacidad de resolver independientemente un problema, y el nivel de desarrollo potencial, determinado a través de la resolución de un problema bajo la guía de un adulto o en colaboración con otro compañero más capaz." (Vygotsky, 1979, p.133).

Aportes a la Educación Actual: Vygotsky realiza aportes fundamentales a la educación con su teoría de zona de desarrollo próximo, en la cual según el autor se da una relación íntima entre el desarrollo y el aprendizaje, permitiendo demostrar la raíz social atribuida al conocimiento humano. Según Vygotsky, los procesos culturales y sociales van a guiar el desarrollo cognitivo en los niños, los cuales realizan una participación activa con el ambiente que los rodea, ya sea para resolver problemas de forma individual 0 potenciando su nivel de desarrollo en la resolución de problemas con la guía de un adulto 0 de alguien más capacitado. Lo anterior hace que el estudiante sea más autónomo $\mathrm{e}$ independiente en sus aprendizajes, esto a su vez se traduce en la evaluación de sus propios logros; se fundamenta la teoría psicológica que relaciona el comportamiento y la mente.

\section{Postulados de Reuven Feuerstein: Teoría de la Modificabilidad Estructural}

La Teoría de la Modificabilidad Cognitiva Estructural, consiste en favorecer el desarrollo de los procesos y estrategias del pensamiento que no sólo están implícitos en las actividades escolares sino también en las situaciones de la vida social y familiar del niño. La modificabilidad de un individuo, se define como la capacidad de partir desde un punto de su desarrollo, en un sentido más o menos diferente de lo predecible hasta ese momento, según su desarrollo mental. Feuerstein considera además los sistemas de necesidades y creencias ya que en toda teoría por muy científica que sea, debe existir la creencia, es decir: que el ser humano puede modificarse.

La teoría de la modificabilidad humana es posible gracias a la intervención de un mediador, el cual se preocupa de dirigir y optimizar el desarrollo de la capacidad intelectual. Los Principios básicos de Feuerstein son: (a) los seres humanos son modificables, rompe con las costumbres genéticas internas y externas; (b) el individuo específico con el que estoy trabajando es modificable; (c) yo soy capaz de cambiar al individuo; (d) yo mismo soy una persona que puede y tiene que ser modificada; (e) la sociedad también tiene y debe ser modificada. El concepto de inteligencia como matriz invariable fijada por factores genéticos 0 ambientales, se hace incompatible con el concepto de inteligencia considerada como capacidad de modificación. El primero parte del organismo como sistema cerrado y pasivo y el segundo lo considera como sistema abierto, receptivo al cambio y a la modificación, y la inteligencia sería como un proceso de autoregulación dinámica, capaz de 
responder a la intervención del medio exterior.

Feuerstein (1980) pone su énfasis en el papel del lenguaje y en el condicionamiento del acto mental en todas sus fases. Para que haya cambios de estructura se debe dar estas características: cohesión entre parte y todo ya que mientras se ejecuta una parte, el organismo actúa en forma distinta produciendo estimulación. El transformismo se refiere a que un individuo puede enfrentar la misma realidad facilitando los procesos. La autoperpetuaciónautorregulación significa todo lo que interviene en los pre-requisitos del pensamiento.

\section{Aportes a la Educación Actual:} Feuerstein, realiza una propuesta innovadora centrada en los actuales enfoques cognitivos los cuales permitirán llevar al sujeto hacia el desarrollo de estructuras afectivas, sociales y cognitivas que se sustenten en la utilización de operaciones mentales básicas, las mismas que harán posible la potenciación de la Inteligencia y el aprender a pensar aprendiendo a aprender. El autor propone estrategias mentales eficaces que permitan saber buscar información, saber cómo usarla, saber cómo elaborarla, saber inferir de esa información y saber aplicar y transferir esa información a nuevas situaciones. Lo anterior se puede dar en cualquier momento de la vida sin importar la edad que tenga el individuo, teniendo presente los desafíos a nivel personal, familiar, social y profesional, de acuerdo a la concepción del ser humano como sistema abierto.

\section{Postulados de Robert Gagné: Teoría Sistémica}

La posición de Gagné se basa en un modelo de procesamiento de información, donde sistematiza un enfoque integrador en el cual se consideran aspectos de las teorías de estímulos-respuesta y de los modelos de procesamiento de información. Es un modelo acumulativo de aprendizaje que plantea ocho tipos de aprendizaje. (a) Aprendizaje de Signos y Señales; (b) Aprendizaje de Respuestas Operantes; (c) Aprendizaje en Cadena; (d) Aprendizaje de Asociaciones Verbales; (e) Aprendizaje de Discriminaciones Múltiples; (f) Aprendizaje de Conceptos; (g) Aprendizaje de Principios; (h) Aprendizaje de Resolución de Problemas.

A la luz de esta teoría, el aprendizaje se define como un cambio en la capacidad 0 disposición humana, relativamente duradero y además no puede ser explicado por procesos de maduración. Este cambio es conductual, lo que permite inferir que se logra sólo a través del aprendizaje. Se encuentra también alteraciones de disposición, que tienen implicancias con respecto de los cambios conductuales, pero de manera diferente. Estas alteraciones se denominan actitud, interés o valor. (Gagné, 1993).

Gagné señala cinco variedades de capacidades que pueden ser aprendidas: (a) destrezas motoras, importante en ciertas áreas del aprendizaje; (b) información verbal, la cual aparece desde que nacemos; (c) destrezas intelectuales, comienza al adquirir discriminaciones y cadenas simples, hasta llegar a conceptos y reglas. (d) actitudes, estas son las capacidades que influyen sobre las acciones individuales de las personas. (e) estrategias cognoscitivas, son destrezas de organización interna, que rigen el comportamiento del individuo con relación a su atención, lectura, memoria, pensamiento, entre otros.

Aportes a la Educación Actual: Gagné plantea la existencia de procesos cognitivos, los cuales son métodos de la persona, para percibir, asimilar y almacenar conocimientos. Habla de destreza mental, cuando uno o más de estos procesos internos ha sido desarrollado a un nivel de eficiencia relativamente alta. Cuando se aplica una destreza mental a una tarea, ya sea por voluntad propia u orden externa, podemos decir que esta destreza funciona como una estrategia cognitiva. Este punto puede ser ejemplificado así: el uso de 
imágenes es un proceso cognitivo básico. En algunas personas que son eficientes en la creación y manejo de imágenes, esto sería una destreza mental. Cuando estas personas usan las imágenes para aprender algo, estas imágenes funcionan cómo estrategias cognitivas.

\section{Postulados de Daniel Goleman: Teoría de la Inteligencia Emocional}

Cuando se habla de inteligencia emocional, se habla de la capacidad del individuo para identificar su propio estado emocional y gestionarlo de forma adecuada. Esta habilidad repercute de forma muy positiva sobre las personas que la poseen, pues les permite entender y controlar sus impulsos, facilitando las relaciones comunicativas con los demás. En esencia, toda emoción constituye un impulso que nos moviliza a la acción. La propia raíz etimológica de la palabra da cuenta de ello, pues el latín movere significa moverse y el prefijo e denota un objetivo (Goleman, 1996).

Alrededor del tallo encefálico, que constituye la región más primitiva de nuestro cerebro y que regula las funciones básicas como la respiración o el metabolismo, se fue configurando el sistema límbico, que aporta las emociones al repertorio de respuestas cerebrales. En esta región cerebral se ubica la amígdala en la que se depositan nuestros recuerdos emocionales y que, por ello mismo, nos permite otorgarle significado a la vida. El pensamiento, la reflexión sobre los sentimientos, la comprensión de símbolos, el arte, la cultura y la civilización encuentran su origen en este esponjoso reducto de tejidos neuronales.

$\mathrm{Su}$ tesis defiende que, con mucha frecuencia, la diferencia radica en ese conjunto de habilidades que ha llamado inteligencia emocional (Goleman, 1996), entre las que destacan: (a) El autocontrol, el arte de contenerse, de dominar los arrebatos emocionales y de calmarse a sí mismo son habilidades que se pueden aprender y desarrollar. (b) El entusiasmo, es el gusto por lo que se hace o el optimismo que representan unos estímulos ideales para el éxito. (c) La empatía, denota la capacidad de percibir la experiencia subjetiva de otra persona, esta capacidad para comprender lo que sienten los demás afecta un espectro muy amplio de actividades. (d) La perseverancia, como la habilidad de persistir y nunca desistir hasta que se haya logrado los objetivos propuestos, depende fundamentalmente de factores emocionales, como el entusiasmo y la tenacidad frente a todo tipo de contratiempos. (e) La capacidad para motivarse a uno mismo, es decir, de sentirse lo suficientemente diestros como para encontrar la forma de alcanzar sus objetivos.

Si bien una parte de estas habilidades pueden venir configuradas en el equipaje genético de todo ser humno, y otras tantas se moldean durante los primeros años de vida, la evidencia respaldada por abundantes investigaciones demuestra que las habilidades emocionales son susceptibles de aprenderse y perfeccionarse a lo largo de la vida, si para ello se utilizan los métodos adecuados.

Aportes a la Educación Actual: Gracias a la neuroplasticidad, que permite moldear el cerebro de una persona hasta los 20 años, los educadores pueden ayudar a niños y jóvenes a alcanzar una mejor madurez. Los avances en la neurociencia muestran cómo si un individuo es emocionalmente inteligente, puede ser capaz de controlar sus impulsos para actuar de acuerdo con la parte más racional de su cerebro. Si se aprende a trabajar la autoconciencia emocional y nuestra propia autogestión, seremos capaces de reaccionar de forma adecuada en momentos de crisis y controlar los impulsos para tomar la mejor decisión.

El profesor debe ayudar a sus estudiantes a mantenerse en el estado denominado como el fluir, el cual es la mejor situación para el cerebro y su rendimiento. Se sitúa en la posición intermedia entre la desmotivación y el estrés. La inteligencia social puede tener una gran influencia en la educación y el liderazgo si el líder (el profesor) es capaz de 
impulsar el cerebro de sus estudiantes y les contagia su actitud y estado emocional. Es fundamental para un profesor que su clase se sienta relajada y disfrute el aprendizaje. En síntesis, canalizar las emociones hacia un fin más productivo constituye una verdadera aptitud maestra.

\section{Postulados de la Neurociencia:}

La neurociencia tiene sus inicios con Hipócrates cuando planteo que del cerebro vienen las alegrías, las delicias, el placer, la risa, también el dolor y los sufrimientos. En 1791 Luigi Galvani descubrió la existencia de actividad eléctrica en los animales. Desde entonces, el estudio de la conducción nerviosa y las consecuencias que lleva, logrando los complejos procesos cognitivos, han sido objeto de arduo estudio. En 1956 se funda la neurociencia cognitiva con el fin de entender cómo las funciones psicológicas son generadas a partir de las neuronas y los circuitos que generan. "La Neurociencia no sólo no debe ser considerada como una disciplina sino que es el conjunto de ciencias cuyo sujeto de investigación es el sistema nervioso con particular interés en cómo la actividad del cerebro se relaciona con la conducta y el aprendizaje" (Salas, 2003, p. 156).

$\mathrm{La}$ tarea central de las llamadas neurociencias es la de intentar explicar cómo es que actúan millones de células nerviosas individuales en el encéfalo para producir la conducta y cómo, a su vez, estas células están influidas por el medio ambiente, incluyendo la conducta de otros individuos (Jessel, Kandel, \& Schwartz, 1997). Precisamente, las neurociencias están contribuyendo a una mayor comprensión, y en ocasiones a dar respuestas a cuestiones de gran interés para los educadores; por ejemplo, hay evidencias según lo muestran las investigaciones de que tanto un cerebro en desarrollo como uno ya maduro se alteran estructuralmente cuando ocurren los aprendizajes.

Con la Neurociencia se ha demostrado que la práctica incrementa el aprendizaje en el cerebro, hay una relación similar entre la cantidad de experiencia en un ambiente complejo y el monto de cambio estructural. Los procesos de aprendizaje y la experiencia propiamente dicha van modelando el cerebro que se mantiene a través de incontables sinapsis; estos procesos son los encargados de que vayan desapareciendo las conexiones poco utilizadas y que tomen fuerza las que son más activas.

Aportes a la Educación Actual: Con los aportes de la neurociencia, hay coincidencia para sostener que patrones o modelos de actividad neural están en correspondencia con estados 0 representaciones mentales particulares. El aprendizaje esencialmente comprende cambios y conexiones: la liberación de neurotransmisores en la sinapsis puede alterarse, o las conexiones entre neuronas pueden reforzarse 0 debilitarse. El éxito de la enseñanza afecta directamente las funciones del cerebro modificando las conexiones. Se podría decir entonces que el ambiente afecta tanto la estructura del cerebro como su funcionalidad; un ambiente apropiado es esencial para conformar partes sustanciales del mismo. Y esta afirmación se podría trasladar con total confianza al ambiente de una clase $y$, aun, a una situación de aprendizaje más amplia.

La mayor parte del tiempo el cerebro lleva a cabo sus conexiones de una manera que se puede llamar aceptable o satisfactoria, pero cuando las conexiones cambian, la personalidad también puede cambiar; si el yo puede desarmarse por las experiencias que modifican las conexiones, también puede volver a armarse por las experiencias que establece, o cambiar o renovar las conexiones. La plasticidad del cerebro habilita aprendizajes a lo largo de la vida. Si bien es cierto que en los jóvenes y sobre todo en la adultez el desarrollo de nuevas neuronas no es tan común, ciertas investigaciones han demostrado que el desarrollo de nuevas vías neurales es más factible de lo que se piensa; nuestras 
sinapsis cambian todo el tiempo y es así como recordamos una experiencia, otra y otra. Cualquier conjunto de estímulos ambientales específicos causan en el cerebro nuevas conexiones y esta habilidad se conserva en el transcurso de la vida. Por ello, es tan importante que los procesos de aprendizaje estén vigentes en ese transcurso; ya que son los desafíos y retos los que movilizan las conexiones.

Postulados de Howard Gardner: Teoría de las Inteligencias Múltiples

Gardner plantea la existencia de ocho inteligencias, a saber: (a) Lingüística, es la capacidad de dominar el lenguaje y poder comunicarnos con los demás es transversal a todas las culturas. (b) Lógico matemática, se vincula a la capacidad para el razonamiento lógico y la resolución de problemas matemáticos. (c) Espacial, es la habilidad para poder observar el mundo y los objetos desde diferentes perspectivas. (d) Musical, donde algunas zonas del cerebro ejecutan funciones vinculadas con la interpretación y composición de música.

(e) Corporal y cenestésica, son las habilidades corporales y motrices que se requieren para manejar herramientas 0 para expresar ciertas emociones. (f) Intrapersonal, inteligencia que faculta para comprender y controlar el ámbito interno de uno mismo. (g) Interpersonal, faculta para poder advertir cosas de las otras personas más allá de lo que nuestros sentidos logran captar. (h) Naturalista, permite detectar, diferenciar y categorizar los aspectos vinculados a la naturaleza. (Gardner, 2005).

Gardner afirma que todas las personas son dueñas de cada una de las ocho clases de inteligencia, aunque cada cual destaca más en unas que en otras, no siendo ninguna de las ocho más importantes 0 valiosas que las demás. Generalmente, se requiere dominar gran parte de ellas para enfrentarnos a la vida, independientemente de la profesión que se ejerza. A fin de cuentas, la mayoría de trabajos precisan del uso de la mayoría de tipos de inteligencia.
Aportes a la Educación Actual: La educación que se de en las aulas se empeña en ofrecer contenidos $y$ procedimientos enfocados a evaluar los dos primeros tipos de inteligencia: lingüística y lógico-matemática. No obstante, esto resulta insuficiente en el proyecto de educar a los alumnos en plenitud de sus potencialidades. La necesidad de un cambio en el paradigma educativo fue llevada a debate gracias a la Teoría de las Inteligencias Múltiples de Gardner. Identificar las fortalezas de los estudiantes en lugar de las carencias, que es lo que se ha hecho normalmente, debería permitir una planificación educativa adecuada. Lo cierto es que aunque todos somos diferentes, con cerebros únicos y singulares, la escuela ha considerado tradicionalmente una única forma de aprendizaje y ha clasificado a los alumnos en función de una capacidad general. En la práctica, no todos los seres humanos aprenden de la misma forma ni tienen los mismos intereses y en un mundo cambiante como el actual, en el que la diversidad de información es una realidad, la elección resulta inevitable.

Las implicaciones educativas de la teoría de las inteligencias múltiples son enormes. Sugiriere a los docentes la necesidad de aplicar estrategias pedagógicas más allá de las lingüísticas y lógicas que predominan en el aula y de adoptar enfoques creativos que se alejen de las tradicionales distribuciones de mesas en filas y columnas con el profesor delante ( $\mathrm{y}$ en muchas ocasiones por encima), de las pizarras o de la dependencia excesiva de los libros de texto. Los nuevos tiempos requieren entornos que fomenten la creatividad y la colaboración.

\section{CONCLUSIONES}

Las Teorías Cognitivas con relación a los objetivos educativos reconocen la necesidad de cambiar el estado de conocimiento del estudiante estimulando la utilización de estrategias de aprendizaje apropiadas. De esta manera se intenta favorecer en el estudiante la comprensión, 
organización y elaboración de la información que recibe. Así, el aprendizaje cognitivo incluye diferentes fases: la de exploración, la de comprensión y la de retención de la información. Esto implica que el estudiante debe pasar de una fase de aprendizaje inductivo (exploración de conceptos) a una de aprendizaje deductivo (aplicación de la información).

El rol del estudiante pasa de pasivo a un estado activo de relaciones entre el material nuevo y sus conocimientos previos. Es un participante activo del proceso de aprendizaje. Algunas estrategias de aprendizaje incluirían el uso de ayudas mnemónicas y visuales, la elaboración de mapas mentales y el uso de metáforas y analogías.

La interacción entre estudiantes se analiza como la producción en masa de conocimiento, descubrimiento y aportes continuos al aprendizaje. Debe ser de apoyo, respeto por la diferencia ya que todos aprendemos de diferente manera y de juicio crítico frente a la percepción de nuevos conocimientos.

El rol del docente debe entender las diferentes experiencias y conocimientos previos de los estudiantes. Así como organizar y estructurar de la manera más efectiva la información según el desempeño y el estilo de aprendizaje de los estudiantes. El docente debe proponer prácticas con retroalimentación para que la nueva información se asimile y se ajuste la estructura cognitiva del estudiante. Es importante también que el docente comprenda si se encuentra ante un estudiante de cerebro izquierdo (más analítico y orientado a la interpretación de textos) o de cerebro derecho (más creativos y orientados a las imágenes), con la finalidad de que el proceso de aprendizaje sea más eficaz. Igualmente explorar los intereses, motivaciones, y emociones que mueven al estudiante en el aula.

En la relación docente alumno la actitud del profesor y su efecto sobre el aprendizaje han sido investigados ampliamente. Independientemente de la edad del estudiante, un profesor amable, considerado y atento propiciará en los estudiantes una mejor actitud para conseguir un nivel alto de aprendizaje cognitivo.

Con relación a los criterios e instrumentos de evaluación esta se centra en el proceso. Aún considerando muy deseable la evaluación en contextos reales 0 realistas, admite y valora la evaluación fuera de tales contextos, al basar en la abstracción una parte fundamental del aprendizaje. Son posibles, por tanto, instrumentos de evaluación basados en la aplicación de conocimientos a la resolución de problemas, aún en situaciones aisladas del contexto real.

\section{REFERENCIAS BIBLIOGRAFICAS}

Ausubel, D. P. (1976). Psicología educativa. Un punto de vista cognoscitivo. México: Trillas.

Bruner, J. (1986). Realidad mental y mundos posibles. Los actos de la imaginación que dan sentido a la experiencia. Barcelona: Gedisa.

Camargo, A. Hederich, C. (2010, Octubre). Jerome Bruner: dos Teorías Cognitivas, dos Formas de Significar, dos Enfoques para la Enseñanza de la Ciencia. Revista Psicogente.

Feuerstein, R. (1980). Learning Potential Assesment Device. Glenview. Illinois: Scott. Foresman and Company.

García, E. (2001). Piaget: la formación de la inteligencia.

Gagné, R. M. (1993). Diseño de la enseñanza para un aprendizaje eficaz. México: McGraw-Hill Interamericana.

Gardner, H. (2005). Inteligencias Múltiples: la teoría en la práctica. [Versión electrónica]. Editorial Paidos. 
Goleman, D. (1996). Inteligencia Emocional. Barcelona: Kairos

Jessel, T., Kandel, E. \& Schwartz, J. (1997). Neurociencia y conducta. Madrid: Prentice Hall.

Mayer, R. (1985). El futuro de la psicología cognitiva. Madrid: Alianza

Ormrod, J.E. (2008). Aprendizaje humano. Madrid: Pearson Educación SA.

Pedraja, M.J. (2001, Noviembre). El conductismo de Edward C. Tolman: Un cordero con piel de lobo. Revista de Historia de la Psicología., Vol. 22.

Piaget, J. (1979). Tratado de lógica y conocimiento científico. Naturaleza y métodos de la epistemología. Buenos Aires: Paidós.

Pozo, J.I. (2006). Teorías cognitivas del aprendizaje. [Versión electrónica]. Ediciones Morata.

Rodríguez, M. (2010). Teoría del aprendizaje significativo en la perspectiva de la psicología cognitiva. [Versión electrónica]. Editorial Octaedro.

Salas R. (2003, Julio). La educación necesita realmente de la neurociencia? Estudios Pedagógicos. Revistas Científicas de América Latina y el Caribe, España y Portugal, 29.

Vygotsky, L.S. (1979). El desarrollo de los procesos psicológicos superiores. Buenos Aires: Grijalbo 